\title{
Calcitonin Gene-Related Peptide in the Bed Nucleus of the Stria Terminalis Produces an Anxiety-Like Pattern of Behavior and Increases Neural Activation in Anxiety-Related Structures
}

\author{
Kelly S. Sink, David L. Walker, Yong Yang, and Michael Davis \\ Department of Psychiatry and Behavioral Sciences, Yerkes National Primate Center, Emory University, Atlanta, Georgia 30329
}

\begin{abstract}
Calcitonin gene-related peptide (CGRP) evokes anxiety-like responses when infused into the lateral ventricle of rats. Because the bed nucleus of the stria terminalis (BNST) lies immediately adjacent to the lateral ventricle, is rich in CGRP receptors, and has itself been implicated in anxiety, we evaluated the hypothesis that these effects are attributable to stimulation of CGRP receptors within the BNST itself. Bilateral intra-BNST, but not dorsal, CGRP infusions $(0,200,400,800 \mathrm{ng} / \mathrm{side})$ enhanced startle amplitude in a dose-dependent manner, and produced an anxiety-like response on the elevated plus maze. Intra-BNST infusion of the CGRP antagonist, $\alpha$ CGRP $_{8-37}$, blocked the effect of CGRP on startle, and also blocked startle potentiation produced by exposure to trimethylthiazoline (a component of fox feces that induces anxiety-like behavior in rats). Intra-BNST, but not dorsal, CGRP infusions also increased c-Fos immunoreactivity in a number of anxiety-related brain areas (central nucleus of the amygdala, locus ceruleus, ventrolateral septal nucleus, paraventricular hypothalamic nucleus, lateral hypothalamus, lateral parabrachial nucleus, dorsal raphe nucleus, and nucleus accumbens shell), all of which receive direct projections from the BNST. Together, the results indicate that the activation of BNST CGRP receptors is both necessary and sufficient for some anxiety responses and that these effects may be mediated by activation of a wider network of BNST efferent structures. If so, inhibition of CGRP receptors may be a clinically useful strategy for anxiety reduction.
\end{abstract}

\section{Introduction}

The bed nucleus of the stria terminalis (BNST), particularly its lateral subdivision, is an important component of anxiety circuitry. In rodents, lesions or inactivation of the BNST reduces stress and anxiety-like behavior in several paradigms (Walker and Davis, 1997; Sullivan et al., 2004; Waddell et al., 2006), while in human and non-human primates, imaging studies have suggested that the BNST is activated by anxiogenic stimuli (Kalin et al., 2005; Straube et al., 2007; Fox et al., 2010; Somerville et al., 2010). Reviewing this growing literature, we have suggested that the BNST participates preferentially in sustained but not phasic threat responses - a pattern complementary to that of the closely related medial division of the central amygdala nucleus. Interestingly, it is these more sustained types of fear responses that appear to be selectively increased in posttraumatic stress and panic disorder patients, and selectively attenuated by established anxiolytics in healthy controls (Grillon et al., 1996). Given this possible link to clinical anxiety, a greater understanding of the BNST and its neuropharmacological regulation seems warranted.

Received 0ct. 7, 2010; revised Nov. 22, 2010; accepted Dec. 2, 2010.

This research was supported by National Institutes of Health Awards MH47840 and MH069056 to M.D., and a National Alliance for Research on Schizophrenia and Depression Young Investigator Award to D.L.W.

Correspondence should be addressed to Dr. Kelly S. Sink, Department of Psychiatry and Behavioral Sciences, Emory University School of Medicine, Atlanta, GA 30329. E-mail: ksink@emory.edu.

DOI:10.1523/JNEUROSCI.5274-10.2011

Copyright $\odot 2011$ the authors $\quad 0270-6474 / 11 / 311802-09 \$ 15.00 / 0$
In this regard, a notable feature of the BNST is the rich variety of neuropeptides and neuropeptide receptors found within. Calcitonin gene-related peptide (CGRP) is one such peptide. CGRP innervation of the BNST arises primarily from parabrachial neurons in the brainstem (Dobolyi et al., 2005) which have been shown previously to be highly stress-responsive (Kainu et al., 1993). Many of the terminals of these parabrachial neurons form perisomatic baskets around BNST cells that express corticotropinreleasing factor (CRF) (Kozicz and Arimura, 2001)-another peptide well known for its involvement in stress and anxiety (Swerdlow et al., 1986; Hauger et al., 2009).

When infused into the lateral ventricle, CGRP evokes various behaviors and other effects suggestive of anxiety. For example, intracerebroventricular (ICV) CGRP infusions evoke fear-like freezing (Poore and Helmstetter, 1996), enhanced acquisition and retrieval and delayed extinction of learned avoidance behavior (Kovács et al., 1995; Kovács and Telegdy, 1995), increases in heart rate and arterial blood pressure (Brown and Gray, 1988), and activation of the hypothalamic-pituitary-adrenal axis (Kovács et al., 1995; Li et al., 2004). As the BNST lies immediately adjacent to the lateral ventricle and contains many CGRP receptors, it is possible that many of these effects are at least partly attributable to actions within the BNST.

With this in mind, the present study had two primary goals. One goal was to evaluate the contribution of BNST CGRP to anxiety-like behavior. For this, we used two behavioral paradigms-potentiation of the acoustic startle reflex and the ele- 
vated plus-maze. A second goal was to evaluate the effect of BNST CGRP on structures previously implicated in stress and anxiety. For this we assessed c-Fos expression as a marker of neuronal activation. We predicted that intra-BNST CGRP infusions would increase anxiety-like behavior and neuronal activation in anxiety-related structures, and that CGRP antagonist infusions would prevent anxiety responses.

\section{Materials and Methods}

\section{Animals}

Male Sprague Dawley rats (Charles River), weighing between 275 and $350 \mathrm{~g}$ at the time of surgery and housed in groups of 4 in $45 \times 20 \times 24 \mathrm{~cm}$ (depth $\times$ width $\times$ height) polycarbonate cages, were maintained on a $12 \mathrm{~h}$ light/dark cycle (lights on at 8:00 A.M.) with food and water available ad libitum. A total of 140 animals were used in these experiments. All procedures were conducted in accordance with U.S. Department of Agriculture, Emory University, and National Institutes of Health standards for the care and use of laboratory animals.

\section{Surgery}

Before surgery, rats were anesthetized with $75 \mathrm{mg} / \mathrm{kg}$ (i.p.) ketamine (Bioniche Pharma) and $0.5 \mathrm{mg} / \mathrm{kg}$ (i.p.) Dexdomitor (Orion Pharma) and also given an analgesic dose of $1.0 \mathrm{mg} / \mathrm{kg}$ (s.c.) meloxicam (Boehringer Ingelheim) to reduce postoperative discomfort. Once unresponsive to tail pinch, rats were placed in a Kopf Instruments stereotaxic frame with the nosebar set to $-3.8 \mathrm{~mm}$ (flat-skull position). For BNST cannulations, $11 \mathrm{~mm}, 26$ gauge guide cannulae (Plastics One, model C315G) were implanted bilaterally $\left(20^{\circ}\right.$ coronal angle - to avoid the lateral ventricle, $0.3 \mathrm{~mm}$ caudal, $5.8 \mathrm{~mm}$ ventral, and $3.8 \mathrm{~mm}$ lateral to bregma). Dorsal control cannulations for experiment 4 were the same as those within BNST except that the cannulae were only lowered $4.0 \mathrm{~mm}$ ventral to bregma. For ICV cannulations, a $6 \mathrm{~mm}, 22$ gauge guide cannula (Plastics One, model $313 \mathrm{G}$ ) was implanted into either the right or left lateral ventricle ( $0.4 \mathrm{~mm}$ caudal, $5.5 \mathrm{~mm}$ ventral, and $1.2 \mathrm{~mm}$ lateral to bregma). For all of these placements, four jeweler screws were attached to the skull, and the entire assembly was cemented in place using Cranioplastic Powder (Plastics One). Stainless steel wires (i.e., stylets) were inserted into the guide cannula to maintain patency. The tip of each extended $1 \mathrm{~mm}$ past the end of the guide cannula. After surgery was complete, $0.5 \mathrm{mg} / \mathrm{kg}$ Antisedan (Orion Pharma) was given to reverse the anesthetic effects. A minimum of $7 \mathrm{~d}$ elapsed between cannula implantation and the onset of behavioral procedures.

\section{Drugs and infusion procedure}

CGRP and the CGRP antagonist $\alpha \mathrm{CGRP}_{8-37}$ (Tocris Bioscience) were prepared fresh on the day of infusion in sterile saline vehicle. Before infusion, the infusion lines (PE-20 polyethylene tubing) and injection cannulae were flushed with $0.1 \%$ BSA to prevent peptide adhesion. Injection cannulae (32 gauge) (Plastics One, model C315I) were used for bilateral BNST infusions ( $0.25 \mu \mathrm{l} / \mathrm{min}, 0.5 \mu \mathrm{l}$ total volume/BNST); 28 gauge injectors were used for unilateral ICV infusions $(0.25 \mu \mathrm{l} / \mathrm{min} 1.0 \mu \mathrm{l}$ total; Plastics One, model C313I). After the infusions were completed, the injection cannulae were left in place for $2 \mathrm{~min}$, whereupon the stylets were placed back into the guide cannula. CGRP doses (200, 400, 800 $\mathrm{ng} /$ side) were based on our own pilot data as well as studies of intraamygdala CGRP effects on fear-related behaviors (Kocorowski and Helmstetter, 2001).

\section{Startle apparatus}

Rats were trained and tested in four identical $8 \times 15 \times 15 \mathrm{~cm}$ Plexiglas and wire mesh cages, each suspended between compression springs within a steel frame located within a custom-designed sound-attenuating chamber. The floor of each cage consisted of four $6.0 \mathrm{~mm}$ diameter stainless steel bars spaced $18 \mathrm{~mm}$ apart. Startle responses were evoked by $50 \mathrm{~ms} 95 \mathrm{~dB}$ white-noise bursts ( $5 \mathrm{~ms}$ rise-decay time, $0-22 \mathrm{kHz}$ ) generated by a Macintosh G3 computer (Apple Computers, Inc.) sound file, amplified by a Tandy amplifier (model MPA-200; RadioShack), and delivered through RadioShack Supertweeter speakers located $4 \mathrm{~cm}$ in front of each cage. Background noise ( $60 \mathrm{~dB}$ wideband) was produced by an
Table 1. Rostrocaudal coordinates (referenced from bregma) for regions of interest examined for c-Fos expression

Anatomical region of interest Rostrocaudal coordinate

Infralimbic/prelimbic cortex

Nucleus accumbens shell

$+2.20 \mathrm{~mm}$

Ventrolateral septal nucleus

Central/basolateral/medial amygdala

Paraventricular/lateral hypothalamus

Locus ceruleus

Lateral parabrachial nucleus

Dorsal raphe nucleus/ventrolateral periaqueductal gray

$+1.20 \mathrm{~mm}$

-0.26 to $-0.30 \mathrm{~mm}$

$-3.14 \mathrm{~mm}$

$-1.80 \mathrm{~mm}$

-9.80 to $-10.04 \mathrm{~mm}$

-9.16 to $-9.30 \mathrm{~mm}$

$-8.00 \mathrm{~mm}$

ACO Pacific white-noise generator (model 3024) and delivered through the same speakers as those used to provide background noise. Sound level measurements were made with a Brüel \& Kjaer model 2235 sound-level meter (A scale; random input) with the microphone (type 4176) located $10 \mathrm{~cm}$ from the center of the speaker, which approximates the distance of the rat's ear from the speaker during testing. Startle response amplitudes were quantified using an accelerometer (model U321AO2; PCB Piezotronics) affixed to the bottom of each cage. Cage movement (e.g., produced by the rats' startle response) resulted in displacement of the accelerometer, which in turn produced a voltage output proportional to the velocity of cage movement. This output was amplified (PCB Piezotronics, model 483B21) and digitized on a scale of $0-9.98$ units by an InstruNET device (model 100B; GW Instruments) interfaced to a Macintosh G3 computer. Startle amplitude was defined as the maximal peakto-peak voltage that occurred during the first $200 \mathrm{~ms}$ after onset of the startle-eliciting white-noise burst. The presentation and sequencing of all stimuli were under the control of the Macintosh G3 computer using custom-designed software (The Experimenter; Glassbeads Inc.).

\section{Elevated plus maze}

The maze was a plus-shaped apparatus consisting of two $50 \times 11 \mathrm{~cm}$ open arms, and two $50 \times 11 \times 40 \mathrm{~cm}$ enclosed arms, elevated $40 \mathrm{~cm}$ from the floor. Testing was conducted in a room illuminated by a single red light bulb over the center of the maze.

\section{Fos-immunohistochemistry and cell counting}

At $150 \mathrm{~min}$ after infusion of CGRP, $\alpha \mathrm{CGRP}_{8-37}$, or saline, rats were anesthetized with chloral hydrate and perfused with physiological saline followed by formalin. The brains were cryoprotected in 30\% sucrose for $4 \mathrm{~d}$ before being sliced into $40 \mu \mathrm{m}$ sections which were incubated overnight in the primary antibody, anti-c-Fos (1:4000, Santa Cruz Biotechnology). They were then incubated for $2 \mathrm{~h}$ in the secondary antibody, biotinylated anti-rabbit conjugate (Jackson ImmunoResearch Laboratory), followed by $30 \mathrm{~min}$ of incubation with avidin and biotinylated horseradish peroxidase macromolecular complex (Vectastain Elite ABC kit, Vector Laboratories). The visualization of c-Fos protein expression was completed using the chromagen diaminobenzidine. The sections were then mounted onto glass microscope slides and coverslipped. Tissue from the different treatment groups was processed together to control for variability in the immunohistochemical reaction. Microscopic images were captured with a MicroFire (Optronics) digital camera attached to an Olympus BX51 microscope using a 10× objective lens. For each anatomical region of interest (selected for its association with anxiety), sections from each animal were chosen from identical or immediately proximate rostrocaudal planes. The rostrocaudal coordinates of these sections referenced from bregma according to the atlas of Paxinos and Watson (1997) are listed in Table 1.

Images of these were prepared using PictureFrame software (Optronics). Individual images were montaged using the GNU Image Manipulation Program (GIMP). For each structure, Fos-immunoreactive (Fos-IR) cells located within the boundaries of each structure were counted unilaterally in two serial sections that were anatomically well matched across the treatment groups. Counting was performed by an observer blind to treatment condition using ImageJ software (a National Institute of Health-sponsored imaging program). The boundaries for each area were determined by comparing Fos-stained tissue with adjacent Nissl-stained 
sections and corresponding stereotaxic atlas plates (Paxinos and Watson, 1997). For each region of interest, the average value of the two serial sections (expressed as counts $/ \mathrm{mm}^{2}$ ) was used for statistical analysis. Reliability of the counting method was verified by recounting a sample of 10 c-Fos immunostained sections, each from a different region of interest. Half of the sections were from vehicle-treated animals, and the other half from animals infused with $800 \mathrm{ng}$ of CGRP into the BNST. The Pearson product-moment correlation between the two sets of counts was $r=$ $0.981(p<0.001)$.

\section{Cannula placement verification}

Rats were killed by chloral hydrate overdose and perfused intracardially with $0.9 \%(\mathrm{w} / \mathrm{v})$ saline followed by $10 \%(\mathrm{v} / \mathrm{v})$ formalin. The brains were then removed and immersed in a $30 \%(\mathrm{w} / \mathrm{v})$ sucrose-formalin solution for at least $3 \mathrm{~d}$, after which $40 \mu \mathrm{m}$ coronal sections were cut through the rostrocaudal extent of the BNST, or in the case of ICV cannulation, through the extent of tissue damage surrounding the implantation site. Every other section was mounted and stained with cresyl violet. A scorer blind to the animal's group assignment and behavioral data assessed cannulae placements. Only those animals with placements meeting the appropriate criteria were included in the behavioral analyses. For the BNST, both cannula tips needed to be within $0.5 \mathrm{~mm}$ of the lateral BNST, medial to the internal capsule, and not penetrating the lateral ventricle. For the control placements of experiment 4, the cannula tips needed to be clearly dorsal to the BNST, and for ICV cannulations (experiment 3), unambiguous evidence of ventricle penetration was required, with no damage to adjacent areas other than those areas dorsal to the ventricle through which the cannulae necessarily passed.

\section{Procedures}

Experiments 1-4: acoustic startle. On each of $2 \mathrm{~d}$ before data collection, rats were acclimated to the test chambers and stimuli. For these sessions, rats were placed into the chambers where, after $5 \mathrm{~min}$, they were presented with 48 startle-eliciting $95 \mathrm{~dB}$ white-noise bursts. For this and all other experiments and tests, the interstimulus interval [ISI] between noise bursts was $30 \mathrm{~s}$. On each of the test days that followed, rats were tested twice- once before and once after vehicle or drug infusion. For all experiments, the preinfusion test consisted of 60 startle-eliciting whitenoise bursts. The postinfusion test, and the drugs infused, varied from one experiment to the next. Rats in experiment $1(n=12)$ received an intra-BNST infusion of 0 (i.e., vehicle alone), 200, 400, or $800 \mathrm{ng} / \mathrm{side}$ CGRP using a counterbalanced Latin-squares design. Immediately thereafter, they were returned to the test chambers for a 120 min postinfusion test (i.e., 240 startle-eliciting noise bursts). Rats in experiment 2 received an intra-BNST infusion of vehicle and, on a separate test day, $400 \mathrm{ng} / \mathrm{side}$ of the CGRP antagonist $\alpha \mathrm{CGRP}_{8-37}$ (counterbalanced within-subjects). Sixty minutes later, they received a second infusion - this time of either vehicle ( $n=14)$ or CGRP ( $400 \mathrm{ng} / \mathrm{side}, n=11)$ using a between-subjects design. Thus, for this experiment, there were two groups of rats (vehicle and CGRP), with each being tested twice- once following pretreatment with vehicle and once following pretreatment with $\alpha \mathrm{CGRP}_{8-37}$. Sixty minutes after the second infusion, these rats were returned to the test chambers for a $60 \mathrm{~min}$ test consisting of 120 startle-eliciting noise bursts. Rats in experiment $3(n=10)$ received an ICV infusion of vehicle and, on a separate test day (counterbalanced within subjects) $1.6 \mu \mathrm{g}$ of CGRP. The postinfusion test for this experiment was the same as for experiment 1 (i.e., $2 \mathrm{~h}$ duration with 240 noise bursts). Rats in experiment 4 (c-Fos) received infusions of either vehicle $(n=6), 800 \mathrm{ng}(n=6)$ CGRP, $800 \mathrm{ng}$ of $\alpha \mathrm{CGRP}_{8-37}$ into the BNST $(n=6)$ or $800 \mathrm{ng}$ of CGRP infused into the striatum (dorsal control; $n=5$ ). After infusion, they were returned to the test chamber for a $120 \mathrm{~min}$ test session (240 noise bursts). Thirty minutes after the end of the test (i.e., $150 \mathrm{~min}$ after the infusion), these rats were anesthetized and perfused in preparation for c-Fos immunohistochemistry.

In those experiments using repeated measures (experiments 1-3), at least $48 \mathrm{~h}$ elapsed between test days. This intertest interval was chosen based on pilot data that found no lingering effect of CGRP or $\alpha \mathrm{CGRP}_{8-37}$ on startle after $48 \mathrm{~h}$. For all experiments, startle responses elicited by the last 120 noise bursts (i.e., those occurring from 60 to $120 \mathrm{~min}$ postinfusion) were averaged and used in the statistical analysis, insofar as the onset latency for CGRP effects on startle was found in experiment 1 to be between 30 and 45 min (see Fig. $2 A$ ).

Experiment 5: inhibition of trimethylthiazoline-enhanced startle. To acclimate animals to the test apparatus, they were placed in the test cages for a 15 min session (30-95 dB white-noise bursts) on each of three consecutive days. On the fourth day, they were given an identical 15 min test session and then infused with either vehicle or $800 \mathrm{ng}$ of $\alpha \mathrm{CGRP}_{8-37}$. Thirty minutes later, a small gauze-lined plastic disk containing either 38 $\mu \mathrm{l}$ of trimethylthiazoline (TMT) or $38 \mu \mathrm{l}$ of water was placed on the outside of the wire mesh cage door and the rats were returned to the testing chambers for another 15 min test session. The odor disks were changed every other test session. Each rat was tested only once. At the end of the experimental sessions, the testing apparatus was wiped with soap and water followed by $70 \%$ isopropyl alcohol and then ventilated with clean air for at least $90 \mathrm{~min}$. TMT and water testing were always conducted on separate days, and at least 2 d elapsed between the TMT and subsequent water test sessions. For both the preinfusion and postinfusion test sessions, the average of the 30 startles was used for statistical analysis.

Experiment 6: elevated plus maze. To minimize the effects of handling stress on test outcomes, each rat was handled for $\sim 2 \mathrm{~min} / \mathrm{d}$ for each of at least $3 \mathrm{~d}$ before testing. Ninety minutes before testing, rats received an intra-BNST infusion of either vehicle $(n=13), 800 \mathrm{ng}$ of CGRP $(n=14)$, or $800 \mathrm{ng}$ of $\alpha \mathrm{CGRP}_{8-37}(n=13)$, after which they were taken to the test room. The apparatus was novel to the subject at the time of testing, and each subject was tested only once. Between subjects, the maze was wiped with Quatricide (Pharmacal). All testing was conducted within $2 \mathrm{~h}$ after the beginning of the dark cycle (i.e., between 7:00 and 9:00 P.M.). A scorer blind to the experimental manipulation recorded four measures for each rat: (1) time spent in the open arms, (2) time spent in the closed arms, (3) number of entries into the open arms, and (4) number of entries into the closed arms. A rat was considered to have entered or spent time in an arm only when all four paws were in the respective arm.

\section{Statistical analyses}

For experiments $1-5$, the mean startle amplitude during the preinfusion and postinfusion test sessions was determined and a percentage change score calculated ([mean postinfusion startle amplitude - mean preinfusion startle amplitude]/[mean preinfusion startle amplitude] $\times 100$ ) (Walker and Davis, 2002). Experiment 1 (intra-BNST dose-response) was analyzed using ANOVA with repeated measures on dose. Experiment 2 (ICV) was analyzed using a paired-sample $t$ test. Experiment 3 (antagonist reversal) was analyzed using factorial ANOVA with $\alpha \mathrm{CGRP}_{8-37}$ or vehicle as a within-subjects factor and CGRP or vehicle as a between-subjects factor. Experiment 4 (c-Fos) behavioral data were analyzed with one-way ANOVA. Experiment 5 (TMT) was analyzed using a completely between-subjects $2 \times 2$ factorial ANOVA with two exposure conditions (TMT or water) and two infusion conditions $\left(\alpha \mathrm{CGRP}_{8-37}\right.$ or vehicle).

For experiment 6 (elevated plus maze), the time spent in the open arms and the number of open-arm entries were expressed as a percentage of total arm activity (open-arm time/(open-arm time + closed-arm time) $\times 100$ ), and total arm entries (open-arm entries/(open-arm entries + closed-arm entries) $\times 100$ ), respectively. A lower percentage of openarm time or open-arm entries are taken as indicating increased anxiety. The total number of closed-arm entries was used as an index of general activity (Pellow and File, 1986; Hogg, 1996). These measures were analyzed using one-way ANOVA. For all behavioral experiments, if the overall ANOVA term was significant, nonorthogonal planned comparisons using the overall error term were used to compare each treatment with the vehicle control condition. The $\alpha$ level for each comparison was kept at 0.05 because the number of comparisons was restricted to the number of treatments minus one (Keppel and Wickens, 2008).

Because the c-Fos histological data did not meet the criteria for analysis with parametric statistics, we used the Kruskal-Wallis ANOVA by ranks. In cases where the overall Kruskal-Wallis term was significant, individual Mann-Whitney $U$ tests were performed to compare each treatment group with vehicle. All inferential statistics were performed using SPSS software (version 16.0.0). 

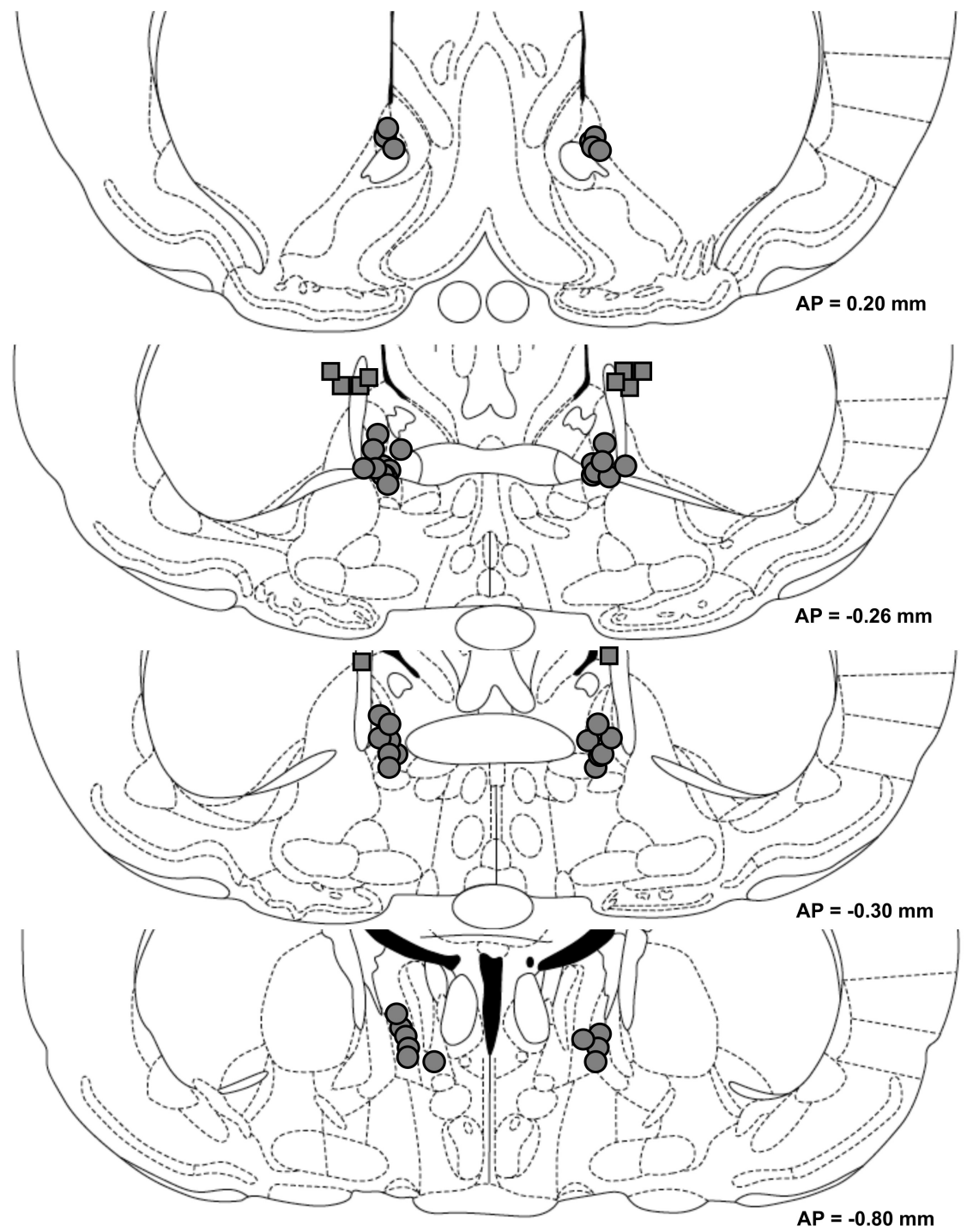

Figure 1. Cannula tip locations of rats included in behavioral analyses. Circles indicate intra-BNST tip placements; squares indicate dorsal control tip placements (experiment 4). The approximate distance posterior to bregma in millimeters is indicated to the right of each figure. Coronal sections are adopted from the atlas of Paxinos and Watson (1997).

\section{Results}

\section{Cannulae placements}

Cannulae placements are shown in Figure 1. All rats included in behavioral analyses had cannula placements that met the inclusion criteria.

\section{BNST CGRP receptor activation increases acoustic startle response}

CGRP enhanced acoustic startle in a dose-dependent manner when infused bilaterally into the BNST (Fig. 2). One-way ANOVA with repeated measures indicated a significant dose effect $\left(F_{(3,33)}=3.33\right.$, $p=0.03)$, and linear regression indicated a highly significant relationship between dose and startle amplitude $\left(F_{(1,11)}=17.12, p=\right.$ 0.002 ). Planned comparisons revealed that 400 and 800 but not 200 ng/side CGRP significantly elevated startle compared with vehicle $(p<0.05)$. In experiment 2 , factorial ANOVA with 400 ng of CGRP or vehicle as a between-subjects factor and $400 \mathrm{ng}$ of intra-BNST $\alpha \mathrm{CGRP}_{8-37}$ or vehicle as the a within-subjects factor revealed a significant effect of CGRP on startle $\left(F_{(1,23)}=6.02, p=0.02\right)$, and also a significant main effect of the antagonist $\left(F_{(1,23)}=7.01, p=0.01\right)$.
Planned comparisons indicated that $\alpha$ CGRP $_{8-37}$ attenuated the startle elevation produced by intra-BNST CGRP $(p<0.05)$, but had no significant effect in rats treated with vehicle (Fig. 3). In separate control experiments designed to evince anatomical specificity of intra-BNST CGRP effects, CGRP infused just dorsal to BNST had no effect on startle (experiment 4; see Fig. 5), and a paired-samples $t$ test showed that intraventricular CGRP infusions $(1.6 \mu \mathrm{g})$ slightly elevated startle compared with the vehicle-treated rats, which exhibited substantial within-session habituation $(t=$ 2.39, $p=0.04$; Fig. 4); however, the mean percentage increase following intraventricular infusions was far lower than the mean percentage increase following intra-BNST infusions of the same total amount in experiment 1 (ICV: $2.3 \pm 7.6 \%$ vs BNST: $127.7 \pm$ $33.8 \% ; t=3.28, p=0.008)$.

\section{BNST CGRP increases neural activation in BNST efferent structures associated with anxiety}

As in experiment 1, intra-BNST CGRP significantly increased startle amplitude compared with vehicle-treated animals. Intra-BNST CGRP antagonist infusions did not increase startle, nor did CGRP infusions dorsal to the BNST (Fig. 5). Table 2 summarizes the c-Fos expression densities in each region of interest following the four different treatments (vehicle, $800 \mathrm{ng}$ / side intra-BNST CGRP, $800 \mathrm{ng} /$ side intraBNST $\alpha \mathrm{CGRP}_{8-37}$, or $800 \mathrm{ng} /$ side CGRP administered dorsal to BNST). The density of Fos-IR cells (expressed as number of cells $/ \mathrm{mm}^{2}$ ) was low in all treatment groups in the basolateral nucleus of the amygdala. The infralimbic cortex, the prelimbic cortex, ventrolateral periaqueductal gray, and the medial amygdala showed moderately dense Fos-IR that was not significantly different between treatment groups. In all of the other regions under investigation (ventrolateral septum, central amygdala, paraventricular hypothalamic nucleus, lateral hypothalamus, locus ceruleus, lateral parabrachial nucleus, nucleus accumbens shell, and dorsal raphe nucleus), intra-BNST CGRP administration significantly increased the density of Fos-immunopositive cells. CGRP infused into a control site dorsal to the BNST (see Fig. 1 for placements) did not affect c-Fos counts in any region of interest (Table 2). However, $800 \mathrm{ng}$ of $\alpha \mathrm{CGRP}_{8-37}$ significantly decreased c-Fos expression in the locus ceruleus and the basolateral nucleus of the amygdala. Representative photomicrographs are shown in Figure 6.

\section{BNST CGRP receptor antagonism blocks TMT-enhanced startle}

Factorial ANOVA indicated a significant influence of TMT $\left(F_{(1,36)}=11.074, p=0.002\right)$ and $\alpha \operatorname{CGRP}_{8-37}\left(F_{(1,36)}=9.298, p=\right.$ $0.004)$ on startle, as well as a significant interaction of these two factors $\left(F_{(1,36)}=4.440, p=0.042\right)$. Planned comparisons re- 

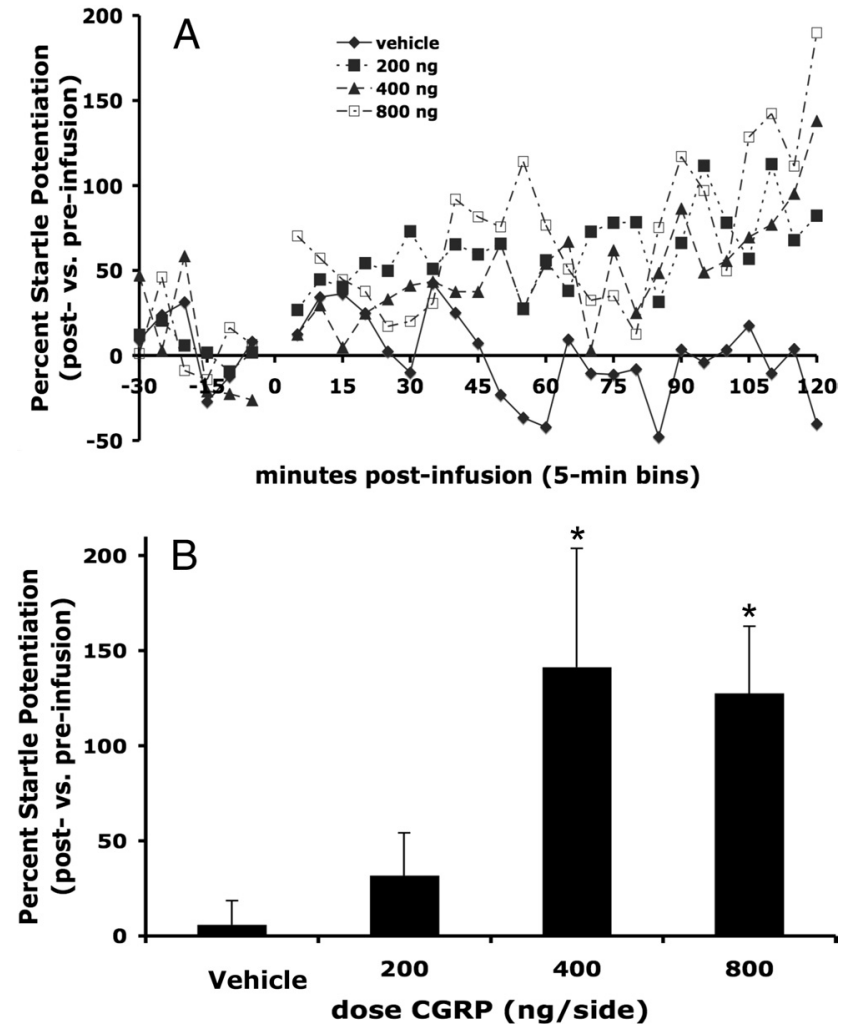

Figure 2. CGRP $(200,400,800 \mathrm{ng} / \mathrm{side})$ infused bilaterally into the lateral BNST increased acoustic startle response in a dose-dependent manner (data are expressed as percentage change compared with preinfusion startle levels for each animal). $\boldsymbol{A}$, Time course of (GRP effects on startle. $\boldsymbol{B}$, Mean ( \pm SEM) percentage change from preinfusion baseline to the final $60 \mathrm{~min}$ of postinfusion testing. Repeated-measures ANOVA indicated a significant effect of dose, and planned comparisons revealed that both 400 and $800 \mathrm{ng}$ produced significant increases compared with vehicle. ${ }^{*} p<0.05$ versus vehicle.

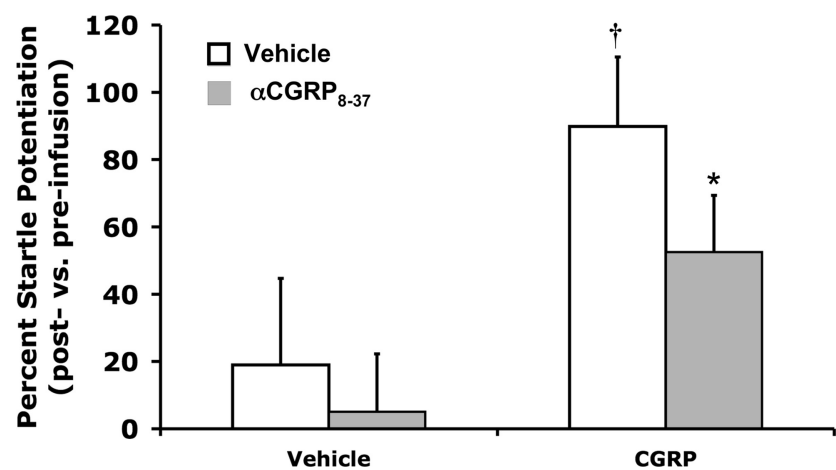

Figure 3. Pretreatment with the (GRP antagonist, $\alpha \mathrm{GRP}_{8-37}(400 \mathrm{ng} / \mathrm{side}$ ) significantly attenuated CGRP-enhanced startle (both infused directly into the BNST), but did not affect startle amplitude when administered before vehicle infusion. Values shown are mean ( \pm SEM) percentage change from the pre- to postinfusion test. ${ }^{\dagger} p<0.05$ versus vehicle/vehicle, ${ }^{*} p<$ 0.05 versus vehicle/CGRP.

vealed that TMT significantly increased startle in saline-treated animals $(p<0.05)$, but intra-BNST $\alpha \mathrm{CGRP}_{8-37}$ blocked TMT-induced startle potentiation. Both treatment groups exposed to water during testing demonstrated similarly low levels of startle (Fig. 7).

BNST CGRP produces an anxiogenic effect in the elevated plus maze but the CGRP antagonist, $\alpha \mathrm{CGRP}_{8-37}$, has no effect Anxiety-like effects of intra-BNST CGRP infusions were also observed on the elevated plus maze. Thus, one-way ANOVA indi-

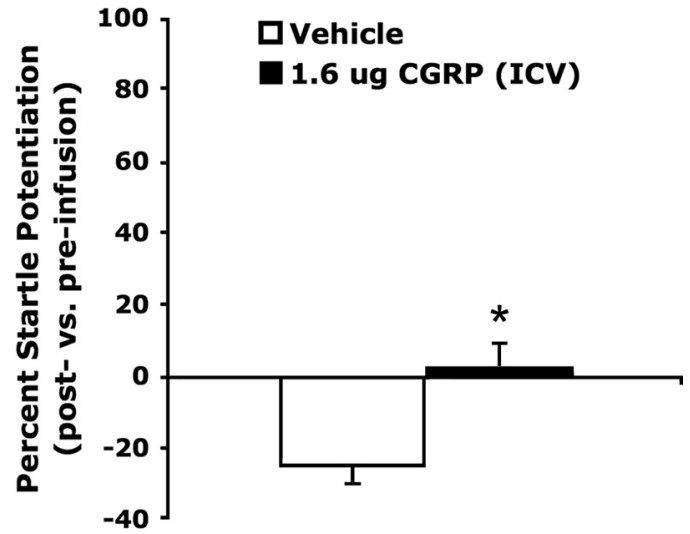

Figure 4. ICV GGRP $(1.6 \mu \mathrm{g})$ significantly increased acoustic startle compared with vehicle Values shown are mean ( \pm SEM) percentage change from the pre- to postinfusion test. ${ }^{*} p<$ 0.05 versus vehicle.

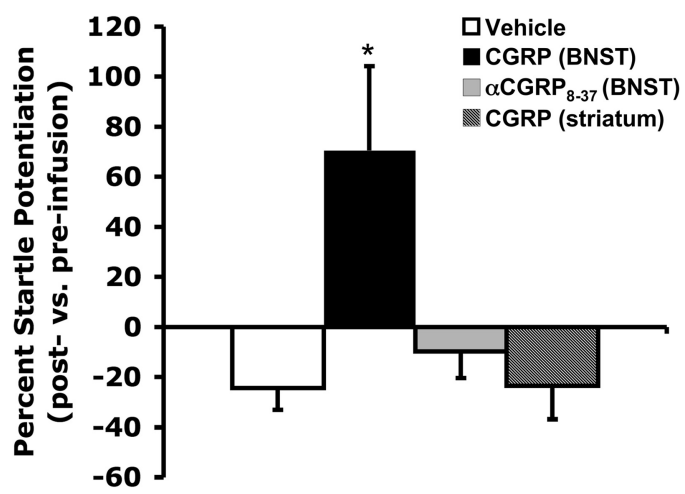

Figure 5. CGRP ( $800 \mathrm{ng} /$ side) infused into but not dorsal to the BNST significantly increased startle amplitude. Intra-BNST infusions of the antagonist, $\alpha \mathrm{GRP}_{8-37}$ did not significantly affect startle amplitude. Values shown are mean ( \pm SEM) percentage change from the pre- to postinfusion test. ${ }^{*} p<0.05$ versus vehicle.

cated a significant treatment effect on the open arm to total arm time ratio $\left(F_{(2,37)}=19.943, p<0.001\right.$; Fig. $\left.8 A\right)$, and open arm entries ratio $\left(F_{(2,37)}=3.353, p=0.046\right.$; Fig. $\left.8 B\right)$. However, the number of closed-arm entries, which is considered to be a measure of general locomotor activity levels (File, 1992; Hogg, 1996), was not significantly affected $\left(F_{(2,37)}=0.962, p=0.39\right.$; Fig. $\left.8 C\right)$. Planned comparisons revealed that 800 ng of CGRP but not 800 ng of $\alpha \mathrm{CGRP}_{8-37}$ significantly decreased the open arm time ratio and open arm entries ratio.

\section{Discussion}

The goals of this study were to evaluate the influence of CGRP within the BNST on anxiety and on neural activation patterns. We found that intra-BNST CGRP infusions produced an anxiogenic behavioral profile and enhanced neural activation in a number of anxiety-related brain areas, and that antagonism of these receptors prevented anxiety-like responses to TMT odor. CGRP infused bilaterally into the BNST enhanced the acoustic startle response in a dose-dependent manner (experiment 1). This increase was attenuated by prior administration of the CGRP antagonist, $\alpha$ CGRP $_{8-37}$, at a dose that did not significantly affect startle when given alone (experiment 2 ). This suggests that the effects on startle were indeed mediated by activation of CGRP receptors. Intra-BNST CGRP infusions (800 ng/side) also decreased the percentage of time spent on the open arms and the percentage of total entries into the open arms of the elevated plus 
Table 2. Effect of intra-BNST CGRP ( $800 \mathrm{ng}$ bilaterally) on c-Fos expression in anxiety, fear, and startle-related neural regions

\begin{tabular}{|c|c|c|c|c|}
\hline Brain area & Vehicle & BNST CGRP & BNST $\alpha$ CGRP $_{8-37}$ & Dorsal control CGRP \\
\hline Infralimbic cortex & $157.9 \pm 25.3$ & $178.9 \pm 28.3$ & $102.3 \pm 27.5$ & $81.2 \pm 26.6$ \\
\hline Prelimbic cortex & $168.7 \pm 48.8$ & $181.6 \pm 24.8$ & $100.5 \pm 26.1$ & $94.2 \pm 17.2$ \\
\hline Ventrolateral septal nucleus & $128.1 \pm 28.1$ & $494.3 \pm 169.9^{\dagger}$ & $63.9 \pm 22.7$ & $105.1 \pm 24.9$ \\
\hline Central nucleus of the amygdala & $87.7 \pm 34.4$ & $356.0 \pm 126.7^{*}$ & $141.9 \pm 36.2$ & $127.2 \pm 26.7$ \\
\hline Basolateral nucleus of the amygdala & $39.4 \pm 4.1$ & $36.9 \pm 4.9$ & $23.0 \pm 4.7^{*}$ & $25.6 \pm 7.0$ \\
\hline Medial nucleus of the amygdala & $88.1 \pm 11.1$ & $159.6 \pm 35.2$ & $82.7 \pm 10.2$ & $64.0 \pm 11.5$ \\
\hline Paraventricular hypothalamic nucleus & $448.0 \pm 95.6$ & $1216.2 \pm 237.1^{\dagger}$ & $401.9 \pm 168.3$ & $465.5 \pm 138.4$ \\
\hline Lateral hypothalamus & $53.7 \pm 6.3$ & $87.6 \pm 13.3^{*}$ & $39.9 \pm 11.4$ & $47.9 \pm 10.6$ \\
\hline Locus ceruleus & $117.9 \pm 48.9$ & $824.4 \pm 145.4^{\dagger}$ & $9.2 \pm 8.4^{\dagger}$ & $366.8 \pm 122.1$ \\
\hline Lateral parabrachial nucleus & $44.3 \pm 11.3$ & $197.8 \pm 22.9^{\dagger}$ & $33.5 \pm 17.0$ & $91.3 \pm 49.1$ \\
\hline Nucleus accumbens shell & $94.1 \pm 35.2$ & $366.3 \pm 34.5^{\dagger}$ & $64.3 \pm 19.8$ & $45.1 \pm 12.1$ \\
\hline Dorsal raphe nucleus & $33.7 \pm 7.2$ & $143.2 \pm 38.0^{\dagger}$ & $20.6 \pm 6.6$ & $62.6 \pm 32.3$ \\
\hline Ventrolateral periaqueductal gray & $52.9 \pm 12.5$ & $83.6 \pm 21.5$ & $32.9 \pm 7.4$ & $55.5 \pm 14.9$ \\
\hline
\end{tabular}

Values are expressed as mean ( \pm SEM) number of c-Fos-positive cells $/ \mathrm{mm}^{2} .{ }^{*} p<0.05,{ }^{\dagger} p<0.01$.
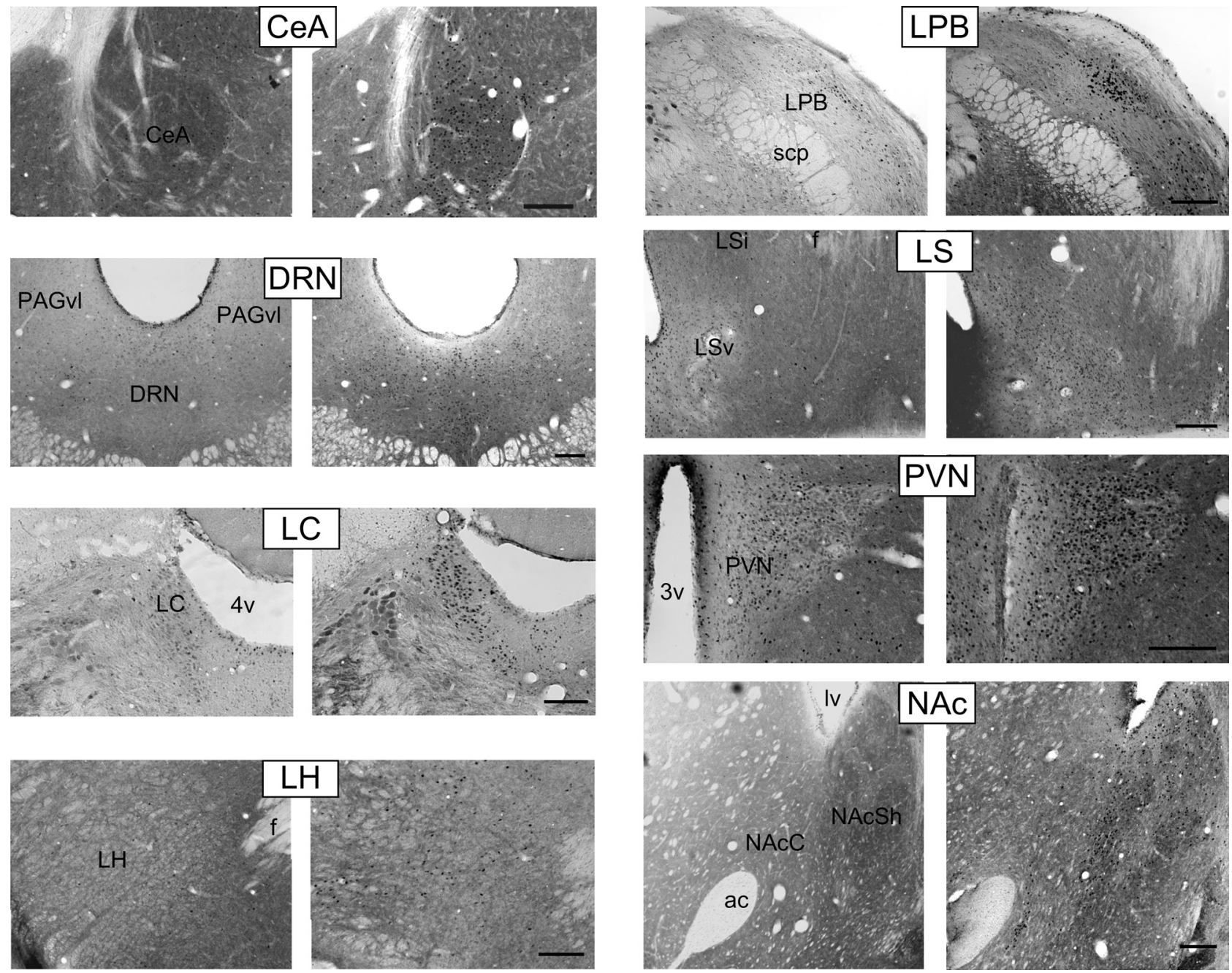

Figure 6. Representative low-magnification bright-field photomicrographs for regions showing significant differences in c-Fos immunoreactivity density between treatment groups. Left panels, vehicle. Right panels, $800 \mathrm{ng}$ bilateral intra-BNST CGRP. Scale bars, $200 \mu \mathrm{m}$. 3v, Third ventricle; 4v, fourth ventricle; ac, anterior commissure; CeA, central nucleus of the amygdala; DRN, dorsal raphe nucleus; f, fornix; LC, locus ceruleus; LH, lateral hypothalamus, LPB, lateral parabrachial nucleus; LSv, ventral lateral septal nucleus; LSi, intermediate lateral septal nucleus; Iv, lateral ventricle; NAcC, nucleus accumbens core; NAcSh, nucleus accumbens shell; PAGvl, ventrolateral periaqueductal gray; PVN, hypothalamic paraventricular nucleus; scp, superior cerebellar peduncle.

maze (experiment 6). These anxiety-like behavioral results are consistent with the data from previous studies which have described the effects of ICV CGRP infusions on other indicators of anxiety-like states including heart rate and arterial blood pressure (Brown and Gray, 1988), hypothalamic-pituitary-adrenal axis activation (Kovács et al., 1995), avoidance learning (Kovács and Telegdy, 1995), and defensive freezing (Poore and Helmstetter, 1996).

The results of experiment 1 indicated a postinfusion onset latency for startle enhancement of $\sim 30-45 \mathrm{~min}$ (Fig. $2 \mathrm{~A}$ ). This 
time course is similar to that which occurs following intra-BNST infusions of the stress-related peptide CRF. Given that CGRPpositive terminals form perisomatic baskets around BNST cells that express CRF (Kozicz and Arimura, 2001), this similarity might not be by chance. For CRF, a variety of experimental results indicate that the effects on startle are mediated by direct actions on BNST neurons (Lee and Davis, 1997). For CGRP however, this time course is also consistent with the possibility that CGRP must first diffuse away from the infusion site (i.e., away from the BNST) to receptors located elsewhere to exert its anxiogenic effect. Of particular concern is the possibility that CGRP may have diffused dorsally, along the cannula track, where it might then enter the lateral ventricle and gain access to a wide range of periventricular and other structures. However, results from experimental controls (experiment 3 and 4) are inconsistent with this possibility. In contrast with the robust acoustic startle potentiation produced by intra-BNST CGRP ( $800 \mathrm{ng} / \mathrm{side}$ ), an equivalent amount of CGRP administered intracerebroventricularly $(1.6 \mu \mathrm{g})$ produced negligible change in startle amplitude (Fig. 4). This suggests that the effects observed with intra-BNST CGRP administration were not due to diffusion into the lateral ventricle. It is also unlikely that the effects of intra-BNST infusions were mediated by CGRP receptors located in structures close to the BNST, such as the nucleus accumbens or lateral septum (Sexton et al., 1986; Kruger et al., 1988; Van Rossum et al., 1994) since CGRP infused at sites just dorsal to the BNST did not produce significant effects on startle or neuronal activation (Fig. 5; Table 2).

Although intra-BNST infusion of $\alpha$ CGRP $_{8-37}$ (400 ng/side) significantly reduced CGRP-mediated startle enhancements, $\alpha \mathrm{CGRP}_{8-37}$ alone did not decrease baseline startle amplitude. This suggests that basal CGRP release (i.e., in the absence of a stressor or anxiogenic stimulus) is relatively low. Perhaps, however, stressful experiences increase CGRP release, which mediates behavioral effects such as those observed upon exogenous CGRP infusion. Indeed, Kainu et al. (1993) have reported that a high percentage of CGRP-expressing neurons located in the external lateral parabrachial nucleus, from which the majority of BNST CGRP afferents originate (Dobolyi et al., 2005), show high levels of c-Fos immunoreactivity following immobilization stress but relatively low levels under baseline conditions. To investigate this possibility here, we evaluated the effect of intra-BNST CGRP antagonist $\left(\alpha \mathrm{CGRP}_{8-37}\right)$ infusions on startle increases produced by TMT odor. TMT, a component of fox feces, induces many anxietyrelated behavioral responses including increased avoidance behavior (Burwash et al., 1998; Holmes and Galea, 2002), increased freezing (Fendt et al., 2003; Hotsenpiller and Williams, 1997; Janitzky et al., 2009; Wallace and Rosen, 2000, 2001), and potentiated acoustic startle (Endres et al., 2005). We found that $\alpha \mathrm{CGRP}_{8-37}$ completely blocked TMTpotentiated startle, but, consistent with results from other experiments in this study, did not have any effects on startle in the control condition (water odor-exposure). Thus, these results are consistent with the view that CGRP-mediated startle increases are physiologically relevant but that a homeostatic perturbation such as that produced by stressful experiences may be required for CGRP release.

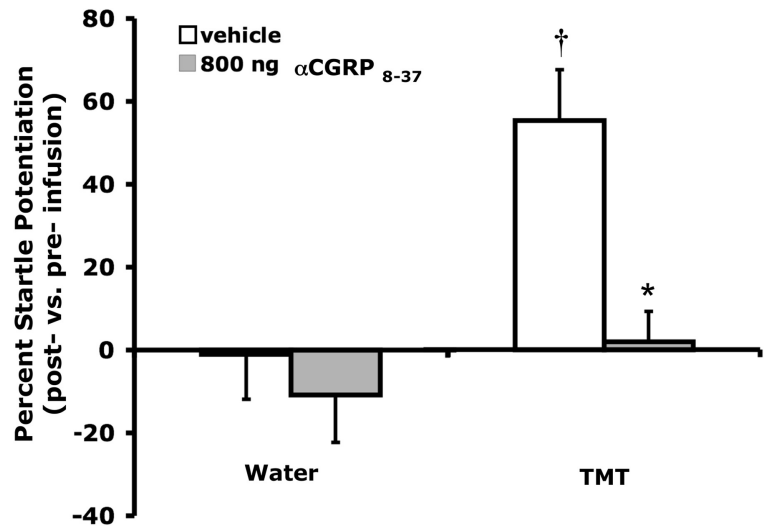

Figure 7. Exposure to TMT odor during testing significantly increased acoustic startle amplitude in vehicle-treated rats (vs water odor). Pretreatment with intra-BNST $\alpha \mathrm{CGRP}_{8-37}(800$ $\mathrm{ng} / \mathrm{side}$ ) blocked this effect, but had no significant influence on startle in water-exposed animals. Values shown are means \pm SEM. ${ }^{\dagger} p<0.05$ versus vehicle-treated animals exposed to water odor, ${ }^{*} p<0.05$ versus vehicle-treated animals exposed to TMT odor. 
Of the many structures activated, the response of the lateral parabrachial nucleus, a structure involved in the integration of peripheral autonomic signals, is especially interesting insofar as the parabrachial nucleus is the primary source of CGRP afferents to the BNST (Dobolyi et al., 2005) and also receives direct projections from the dorsolateral BNST (Dong et al., 2001; Dong and Swanson, 2003). This reciprocal connectivity suggests that CGRP signaling in the BNST is not merely a feedforward activator of anxiety-related structures, but may be part of a feedback loop that integrates autonomic information into the regulation of anxiety states.

It is important to note that not all areas analyzed for Fos were activated by intra-BNST CGRP infusions. Although the prelimbic and infralimbic cortices are implicated in fear and anxiety (Jinks and McGregor, 1997; Quirk et al., 2003), as are the basolateral and medial amygdaloid nuclei (Paré et al., 2004; Rosen, 2004), intra-BNST CGRP failed to significantly affect Fos-IR counts in these regions. Although low expression of c-Fos does not conclusively indicate a lack of neural activation, it is interesting that the prelimbic and infralimbic cortical areas and the basolateral and medial amygdaloid nuclei appear to receive little direct excitatory input from lateral BNST subdivisions (Dong et al., 2000, 2001; Dong and Swanson, 2003; Larriva-Sahd, 2004). This suggests that the strongest influence of BNST CGRP signaling is on those regions receiving substantial excitatory projections from the lateral BNST.

In conclusion, the results from these experiments provide evidence that CGRP receptor activation within the BNST produces an anxiety-like behavioral profile and induces neural activation in BNST efferent structures implicated in anxiety. The fact that the CGRP antagonist $\alpha \mathrm{CGRP}_{8-37}$ alone had no significant impact on acoustic startle amplitude or plus-maze behavior and had minimal effects on neuronal activation implies that endogenous CGRP tone was low under those test conditions. However, blockade of TMT-enhanced startle by $\alpha$ CGRP $_{8-37}$ suggests that, like many neuropeptides, high levels of stress or other homeostatic challenge may be required to induce CGRP release into the BNST. Moreover, the reciprocal connections between the BNST and the CGRP-containing cells in the parabrachial nucleus could potentially set up a positive feedback network during high stress levels that might lead to pathological increases in anxiety.

Further studies will be conducted to determine the relevance of endogenous BNST CGRP to stress-induced anxiety behavior and neuroendocrine responses, and to characterize the mechanisms by which CGRP influences these functions. We propose that CGRP signaling within the BNST is an important modulatory influence in the neural circuitry governing anxiety. If, as many believe, clinical anxiety reflects inappropriate or maladaptive activation of this circuitry, then inhibition of CGRP receptor signaling may be clinically beneficial in the treatment of some anxiety disorders.

\section{References}

Brown MR, Gray TS (1988) Peptide injections into the amygdala of conscious rats: effects on blood pressure, heart rate and plasma catecholamines. Regul Pept 21:95-106.

Burwash MD, Tobin ME, Woolhouse AD, Sullivan TP (1998) Laboratory evaluation of predator odors for eliciting an avoidance response in roof rats (Rattus rattus). J Chem Ecol 24:49-66.

Canteras NS, Goto M (1999) Fos-like immunoreactivity in the periaqueductal gray of rats exposed to a natural predator. Neuroreport 10:413-418.

Dobolyi A, Irwin S, Makara G, Usdin TB, Palkovits M (2005) Calcitonin gene-related peptide-containing pathways in the rat forebrain. J Comp Neurol 489:92-119.
Dong H, Petrovich GD, Swanson LW (2000) Organization of projections from the juxtacapsular nucleus of the BST: a PHAL study in the rat. Brain Res 859:1-14.

Dong HW, Swanson LW (2003) Projections from the rhomboid nucleus of the bed nuclei of the stria terminalis: implications for cerebral hemisphere regulation of ingestive behaviors. J Comp Neurol 463:434-472.

Dong HW, Petrovich GD, Watts AG, Swanson LW (2001) Basic organization of projections from the oval and fusiform nuclei of the bed nuclei of the stria terminalis in adult rat brain. J Comp Neurol 436:430-455.

Duncan GE, Knapp DJ, Breese GR (1996) Neuroanatomical characterization of Fos induction in rat behavioral models of anxiety. Brain Res 713:79-91.

Endres T, Apfelbach R, Fendt M (2005) Behavioral changes induced in rats by exposure to trimethylthiazoline, a component of fox odor. Behav Neurosci 119:1004-1010.

Fendt M, Endres T, Apfelbach R (2003) Temporary inactivation of the bed nucleus of the stria terminalis but not of the amygdala blocks freezing induced by trimethylthiazoline, a component of fox feces. J Neurosci 23:23-28.

File SE (1992) Behavioural detection of anxiolytic action. In: Experimental approaches to anxiety and depression (Elliott JM, Heal DJ, Marden CA, eds), pp 25-44. New York: Wiley Ltd.

Fox AS, Shelton SE, Oakes TR, Converse AK, Davidson RJ, Kalin NH (2010) Orbitofrontal cortex lesions alter anxiety-related activity in the primate bed nucleus of stria terminalis. J Neurosci 30:7023-7027.

Grillon C, Morgan CA, Southwick SM, Davis M, Charney DS (1996) Baseline startle amplitude and prepulse inhibition in Vietnam veterans with posttraumatic stress disorder. Psychiatry Res 64:169-178.

Hauger RL, Risbrough V, Oakley RH, Olivares-Reyes JA, Dautzenberg FM (2009) Role of CRF receptor signaling in stress vulnerability, anxiety, and depression. Ann N Y Acad Sci 1179:120-143.

Hogg S (1996) A review of the validity and variability of the elevated plusmaze as an animal model of anxiety. Pharmacol Biochem Behav 54:21-30.

Holmes MM, Galea LA (2002) Defensive behavior and hippocampal cell proliferation: differential modulation by naltrexone during stress. Behav Neurosci 116:160-168.

Hotsenpiller G, Williams J (1997) A synthetic predator odor (TMT) enhances conditioned analgesia and fear when paired with a benzodiazepine receptor inverse agonist (FG-7142). Psychobiology 25:83-88.

Janitzky K, Stork O, Lux A, Yanagawa Y, Schwegler H, Linke R (2009) Behavioral effects and pattern of brain c-fos mRNA induced by 2,5-dihydro2,4,5-trimethylthiazoline, a component of fox feces odor in GAD67-GFP knock-in C57BL/6 mice. Behav Brain Res 202:218-224.

Jinks AL, McGregor IS (1997) Modulation of anxiety-related behaviours following lesions of the prelimbic or infralimbic cortex in the rat. Brain Res 772:181-190.

Kainu T, Honkaniemi J, Gustafsson JA, Rechardt L, Pelto-Huikko M (1993) Co-localization of peptide-like immunoreactivities with glucocorticoid receptor- and Fos-like immunoreactivities in the rat parabrachial nucleus. Brain Res 615:245-251.

Kalin NH, Shelton SE, Fox AS, Oakes TR, Davidson RJ (2005) Brain regions associated with the expression and contextual regulation of anxiety in primates. Biol Psychiatry 58:796-804.

Keppel G, Wickens, T.D. (2008) Design and analysis: a researcher's handbook: Prentice Hall.

Kocorowski LH, Helmstetter FJ (2001) Calcitonin gene-related peptide released within the amygdala is involved in Pavlovian auditory fear conditioning. Neurobiol Learn Mem 75:149-163.

Kovács A, Telegdy G (1995) Effects of CGRP on active avoidance behavior in rats. Physiol Behav 58:429-435.

Kovács A, Biró E, Szeleczky I, Telegdy G (1995) Role of endogenous CRF in the mediation of neuroendocrine and behavioral responses to calcitonin gene-related peptide in rats. Neuroendocrinology 62:418-424.

Kozicz T, Arimura A (2001) Axon terminals containing CGRP-immunoreactivity form synapses with CRF- and Met-enkephalin-immunopositive neurons in the laterodorsal division of the bed nucleus of the stria terminalis in the rat. Brain Res 893:11-20.

Kruger L, Mantyh PW, Sternini C, Brecha NC, Mantyh CR (1988) Calcitonin gene-related peptide (CGRP) in the rat central nervous system: patterns of immunoreactivity and receptor binding sites. Brain Res 463:223-244.

Larriva-Sahd J (2004) Juxtacapsular nucleus of the stria terminalis of the 
adult rat: extrinsic inputs, cell types, and neuronal modules: a combined Golgi and electron microscopic study. J Comp Neurol 475:220-237.

Lee Y, Davis M (1997) Role of the hippocampus, the bed nucleus of the stria terminalis, and the amygdala in the excitatory effect of corticotropinreleasing hormone on the acoustic startle reflex. J Neurosci 17:64346446.

Li XF, Bowe JE, Mitchell JC, Brain SD, Lightman SL, O’Byrne KT (2004) Stress-induced suppression of the gonadotropin-releasing hormone pulse generator in the female rat: a novel neural action for calcitonin gene-related peptide. Endocrinology 145:1556-1563.

Paré D, Quirk GJ, Ledoux JE (2004) New vistas on amygdala networks in conditioned fear. J Neurophysiol 92:1-9.

Paxinos G, Watson, C. (1997) The rat brain in stereotaxic coordinates, Ed 3. San Diego: Academic.

Pellow S, File SE (1986) Anxiolytic and anxiogenic drug effects on exploratory activity in an elevated plus-maze: a novel test of anxiety in the rat. Pharmacol Biochem Behav 24:525-529.

Poore LH, Helmstetter FJ (1996) The effects of central injections of calcitonin gene-related peptide on fear-related behavior. Neurobiol Learn Mem 66:241-245.

Quirk GJ, Likhtik E, Pelletier JG, Paré D (2003) Stimulation of medial prefrontal cortex decreases the responsiveness of central amygdala output neurons. J Neurosci 23:8800-8807.

Rosen JB (2004) The neurobiology of conditioned and unconditioned fear: a neurobehavioral system analysis of the amygdala. Behav Cogn Neurosci Rev 3:23-41.

Sexton PM, McKenzie JS, Mason RT, Moseley JM, Martin TJ, Mendelsohn FA (1986) Localization of binding sites for calcitonin gene-related peptide in rat brain by in vitro autoradiography. Neuroscience 19:1235-1245.

Silveira MC, Sandner G, Graeff FG (1993) Induction of Fos immunoreactivity in the brain by exposure to the elevated plus-maze. Behav Brain Res $56: 115-118$

Singewald N, Sharp T (2000) Neuroanatomical targets of anxiogenic drugs in the hindbrain as revealed by Fos immunocytochemistry. Neuroscience 98:759-770.

Singewald N, Salchner P, Sharp T (2003) Induction of c-Fos expression in specific areas of the fear circuitry in rat forebrain by anxiogenic drugs. Biol Psychiatry 53:275-283.

Sink KS, Segovia KN, Sink J, Randall PA, Collins LE, Correa M, Markus EJ, Vemuri VK, Makriyannis A, Salamone JD (2010) Potential anxiogenic effects of cannabinoid CB1 receptor antagonists/inverse agonists in rats: comparisons between AM4113, AM251, and the benzodiazepine inverse agonist FG-7142. Eur Neuropsychopharmacol 20:112-122.

Somerville LH, Whalen PJ, Kelley WM (2010) Human bed nucleus of the stria terminalis indexes hypervigilant threat monitoring. Biol Psychiatry 68:416-424.

Straube T, Mentzel HJ, Miltner WH (2007) Waiting for spiders: brain activation during anticipatory anxiety in spider phobics. Neuroimage 37:1427-1436.

Sullivan GM, Apergis J, Bush DE, Johnson LR, Hou M, Ledoux JE (2004) Lesions in the bed nucleus of the stria terminalis disrupt corticosterone and freezing responses elicited by a contextual but not by a specific cueconditioned fear stimulus. Neuroscience 128:7-14.

Swerdlow NR, Geyer MA, Vale WW, Koob GF (1986) Corticotropinreleasing factor potentiates acoustic startle in rats: blockade by chlordiazepoxide. Psychopharmacology (Berl) 88:147-152.

Van Rossum D, Ménard DP, Fournier A, St-Pierre S, Quirion R (1994) Binding profile of a selective calcitonin gene-related peptide (CGRP) receptor antagonist ligand, [125I-Tyr]hCGRP8-37, in rat brain and peripheral tissues. J Pharmacol Exp Ther 269:846-853.

Veening JG, Böcker KB, Verdouw PM, Olivier B, De Jongh R, Groenink L (2009) Activation of the septohippocampal system differentiates anxiety from fear in startle paradigms. Neuroscience 163:1046-1060.

Waddell J, Morris RW, Bouton ME (2006) Effects of bed nucleus of the stria terminalis lesions on conditioned anxiety: aversive conditioning with long-duration conditional stimuli and reinstatement of extinguished fear. Behav Neurosci 120:324-336.

Walker DL, Davis M (1997) Double dissociation between the involvement of the bed nucleus of the stria terminalis and the central nucleus of the amygdala in startle increases produced by conditioned versus unconditioned fear. J Neurosci 17:9375-9383.

Walker DL, Davis M (2002) Quantifying fear potentiated startle using absolute versus proportional increase scoring methods: implications for the neurocircuitry of fear and anxiety. Psychopharmacology (Berl) 164:318-328.

Wallace KJ, Rosen JB (2000) Predator odor as an unconditioned fear stimulus in rats: elicitation of freezing by trimethylthiazoline, a component of fox feces. Behav Neurosci 114:912-922.

Wallace KJ, Rosen JB (2001) Neurotoxic lesions of the lateral nucleus of the amygdala decrease conditioned fear but not unconditioned fear of a predator odor: comparison with electrolytic lesions. J Neurosci 21:3619-3627. 